\title{
Ion beam techniques for nuclear waste management
}

\author{
Markus Schiffer ${ }^{1, *}$, Alexander Stolz ${ }^{1}$, Erik Strub $^{2}$, Susan Herb $^{1}$, Matthias Dewald ${ }^{3}$, Raphael Margreiter ${ }^{2}$, \\ Timm-Florian Papst ${ }^{1}$, Kevin Geusen ${ }^{1}$, Yannik Jakobi ${ }^{1}$, Gereon Hackenberg ${ }^{1}$, Claus Mueller-Gatermann ${ }^{1}$, \\ Stefan Heinze ${ }^{1}$, and Alfred Dewald ${ }^{1}$ \\ ${ }^{1}$ Institute for Nuclear Physics, University of Cologne, Germany \\ ${ }^{2}$ Division for Nuclear Chemistry, University of Cologne, Germany \\ ${ }^{3}$ Gesellschaft für Anlagen- und Reaktorsicherheit gGmbH, Cologne, Germany
}

\begin{abstract}
An automated $\mathrm{CO}_{2}$ gas handling and injection system was developed. It is designed to dilute $\mathrm{CO}_{2}$ samples with blank gas in a mixing volume. The system is intended to be used for the characterization and quantification of ${ }^{14} \mathrm{C}$ content in reactor graphite with accelerator mass spectrometry. A $100 \mathrm{kV}$ accelerator system was developed to measure samples with high ${ }^{14} \mathrm{C}$ content, to test the gas injection system and to measure the ${ }^{3} \mathrm{H}$ content from gaseous releases of reactor graphite. Additionally, the Tandetron model 4130 was purchased from the Max-Planck Institute for Biogeochemistry Jena (Germany) and a concept was developed for installation at the accelerator building of the University of Cologne. With the new $3 \mathrm{MV}$ system, new isotopic ratio measurements and ion beam techniques for material analysis can be performed. The system will be used for nuclear waste management measurements of isotopes, e.g. ${ }^{3} \mathrm{H},{ }^{14} \mathrm{C},{ }^{36} \mathrm{Cl},{ }^{41} \mathrm{Ca}$ and ${ }^{55} \mathrm{Fe}$, which are difficult to measure with other techniques.
\end{abstract}

\section{Introduction}

For the worldwide 250,000 tons of neutron-irradiated reactor graphite, currently no comprehensive disposal strategy exists [1]. The disposal of 1000 tons of neutron-irradiated reactor graphite represents an unsolved task in Germany. In contrast to other countries, this activated graphite does not come from breeding reactors, but originates from reflectors and thermal columns of research reactors or parts of fuel balls and other structures from the prototype reactors AVR (Arbeitsgemeinschaft Versuchsreaktor) in Jülich and the THTR-300 (Thorium High Temperature Reactor) in Hamm-Uentrop.

For the 500 tons from the reflector of the THTR-300, low levels of fission products and, due to the short operating time, only a relatively low neutron activation can be expected. Therefore possibly larger proportions of the material can be released for conventional disposal, if a suitable pre-treatment and a reliable characterisation is available.

The difficulty for the disposal of reactor graphite is the large amount of mobilisable activation products and the release of gaseous substances under repository conditions. This includes several long lived beta-emitters which are difficult to measure with common techniques like liquid scintillation counting, e.g. ${ }^{3} \mathrm{H},{ }^{14} \mathrm{C}$ and ${ }^{36} \mathrm{Cl}$. The radioactive inventory is dominated by ${ }^{14} \mathrm{C}$, which is partly in the same chemical form as the matrix itself. Current pretreatment approaches aim to reduce the ${ }^{14} \mathrm{C}$ fraction, found in the pores of the reactor graphite by controlled heating.

*e-mail: mschiffer@ikp.uni-koeln.de
This proportion comes mainly from the activation of the pore ${ }^{14} \mathrm{~N}$ and ${ }^{17} \mathrm{O}$. It is therefore in a different chemical form and can be depleted selectively [2].

The Cologne center for accelerator mass spectrometry [3], CologneAMS, has started an intense program for studying the applicability of accelerator mass spectrometry of nuclides like ${ }^{3} \mathrm{H},{ }^{14} \mathrm{C},{ }^{36} \mathrm{Cl}$ and ${ }^{41} \mathrm{Ca}[4]$ in nuclear waste. It proposes a new precise and reliable way for the quantification of the radioactive material by the means of direct atom counting. CologneAMS currently uses a $6 \mathrm{MV}$ AMS system from HVEE and a dedicated AMS beamline for medium mass isotopes at the $10 \mathrm{MV} F N$ tandem accelerator [5]. The $6 \mathrm{MV}$ AMS system was subsequently extended by a gas ion source and a gas handling system, dedicated for small ${ }^{14} \mathrm{C}$ samples, e.g. in-situ produced cosmogenic nuclides [6]. Two new accelerator systems, with a terminal voltage of $100 \mathrm{kV}$ and $3 \mathrm{MV}$ respectively, will be built up, because reactor graphite material must not compromise the 6-MV AMS system which is used for our routine radiocarbon measurements.

\section{The $\mathrm{CO}_{2}$ gas handling system}

For automated characterization and quantification of ${ }^{14} \mathrm{C}$ content in reactor graphite with accelerator mass spectrometry, a new $\mathrm{CO}_{2}$ gas handling and injection system for reliable industrial use was developed, funded by the FORKA C14-AMS project, funding number 1559410B. The system is designed to avoid background problems and complex sample preparation, related to the standard liquid 
scintillation counting (LSC) method, by the use of $\mathrm{CO}_{2}$ gas injection to an accelerator mass spectrometer.

To convert the reactor graphite into $\mathrm{CO}_{2}$ an elemental analyzer (EA) is used. This gas, with high ${ }^{14} \mathrm{C}$ concentration, is then diluted with blank $\mathrm{CO}_{2}$ gas in a mixing volume of the dedicated gas handling system, Fig. 1. and transferred to a gas ion source, where negative ions are produced. With the accelerator mass spectrometer the $\left({ }^{14} \mathrm{C} /{ }^{12} \mathrm{C}\right)$ isotopic ratios are determined. The total activity is then calculated from the total sample mass.

The new gas handling system was developed in house from the knowledge and longtime experience with the gas handling system of Ionplus for radiocarbon measurements [7] used in combination with the HVEE (High Voltage Engineering Europe) ion source [6]. The new system is designed for $\mathrm{CO}_{2}$ gas measurements from different sources: either from an elemental analyzer (EA) or from a graphite pretreatment system for controlled heating. The $\mathrm{CO}_{2}$ gas is guided with a He flow to a zeolite trap, where it is accumulated. By controlled zeolite trap heating, the $\mathrm{CO}_{2}$ is released. It can be drawn in the gas-tight syringe, by a negative pressure when the syringe is driven to the backward position by a stepping motor. The system contains a mixing volume, which can be evacuated, filled from the syringe and from gases in storage reservoirs, e.g. standard and blank gas. The dilution of the sample with blank $\mathrm{CO}_{2}$ can be performed likewise in the mixing volume and in the syringe. With the syringe, the sample gas can be passed under constant flow into the ion source. The entire process is controlled by the gas pressure, monitored with a single pressure sensor. In contrast to the Ionplus system, there are no bonded pipe connections, because only cutting ring fittings are used.

The graphite pretreatment system will be developed for controlled heating of reactor graphite samples with an inductive heating system in vacuum environment. The sample will be placed in a tungsten sample holder inside a quartz tube surrounded by the induction coil. The released gas is directed into the ion source via the gas system, where it can be diluted. In addition, the measurement of other beta-emitters like ${ }^{3} \mathrm{H}$ and ${ }^{36} \mathrm{Cl}$ from the same gasphase of the graphite will be developed. The verification of the new measurement technology will be proven by test graphite samples, irradiated with defined neutron flux and defined irradiation times at the TRIGA reactor Mainz.

\section{The 100 kV Tandem Accelerator}

A risk in the measurement of reactor graphite is the contamination of the AMS system. For this reason, a $100 \mathrm{kV}$ accelerator system was developed to measure samples with high ${ }^{14} \mathrm{C}$ content, that can be used to test the gas system until the mixing can be carried out reliably. This system is additionally dedicated for ${ }^{3} \mathrm{H}$ measurements and extends the Cologne negative ion source test bench, Fig. 2 It consists of an ion source high voltage deck, for the use of a Middleton-Type or a NEC MC-SNICS ion source, and a double focusing $90^{\circ}$ analyzing magnet, $\rho=500 \mathrm{~mm}$. The magnet is designed for high momentum resolution and high transmissions. The new $100 \mathrm{kV}$ Tandem accelerator

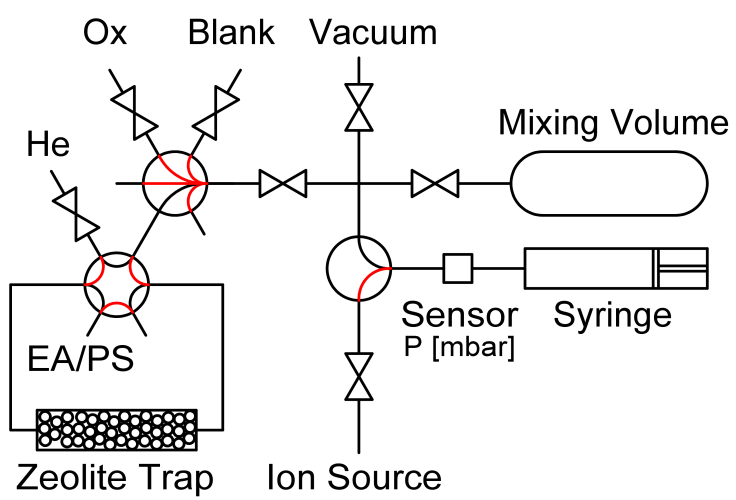

Figure 1. Dedicated gas mixing and injection system for the measurement of $\left({ }^{14} \mathrm{C} /{ }^{12} \mathrm{C}\right)$ isotopic ratios from neutron-irradiated reactor graphite. The system can measure $\mathrm{CO}_{2}$ from an elemental analyzer (EA) or from the graphite pretreatment system (PS)

was designed with an $1 \mathrm{~m}$ acceleration tube and a carbon foil stripper. A special single stripper foil unit was developed with an easy to use foil changing tool. The high voltage will be generated by a commercial power supply. On the high energy side of the accelerator, a magnetic doublet quadrupole lens is used to focus the ion beam in front of the new installed high energy analysing magnet. This magnet was formerly operated at the Cologne $0.6 \mathrm{MV}$ single ended accelerator and the magnetic field of $0.77 \mathrm{~T}$ is suitable to bend ${ }^{3} \mathrm{H}^{+}$with $350 \mathrm{keV}$ ion energy. The bending radius of the magnet is $190 \mathrm{~mm}$ and the iron gap is $25.4 \mathrm{~mm}$. With the vertical acceptance of the vacuum chamber $(14 \mathrm{~mm})$ a calculated transmission of approx. $80 \%$ can be reached. The vertical acceptance is limited because of the needed mechanical stability. A new vacuum chamber was designed for the use of offset Faraday cups in a standard ISO-160 double-cross. It is planned to use a silicon detector for the detection of the radionuclides downstream the analyzing magnet.

The whole setup will be controlled by programmable logic controller (PLC), Siemens S7 type. The LabVIEW based control software, used at the FN accelerator, is suitable for this setup with minor changes for the different setup components.

\section{The 3 MV Tandem Accelerator}

The Institute for Nuclear Physics of the University of Cologne has purchased the 3 MV Tandetron model 4130 from the Max-Planck Institute for Biogeochemistry Jena (Germany), including the main components of the high energy mass spectrometer; the quadrupole doubled lens, the $110^{\circ}$ analyzing magnet and the $33^{\circ}$ electrostatic analyzer. The HVEE AMS system is dedicated for ${ }^{14} \mathrm{C}$ measurements[8].

The installation of the new 3 MV AMS system at the Institute for Nuclear Physics of the University of Cologne will open up a wide range of applications like nuclear waste management measurements, as the FORKA C14- 


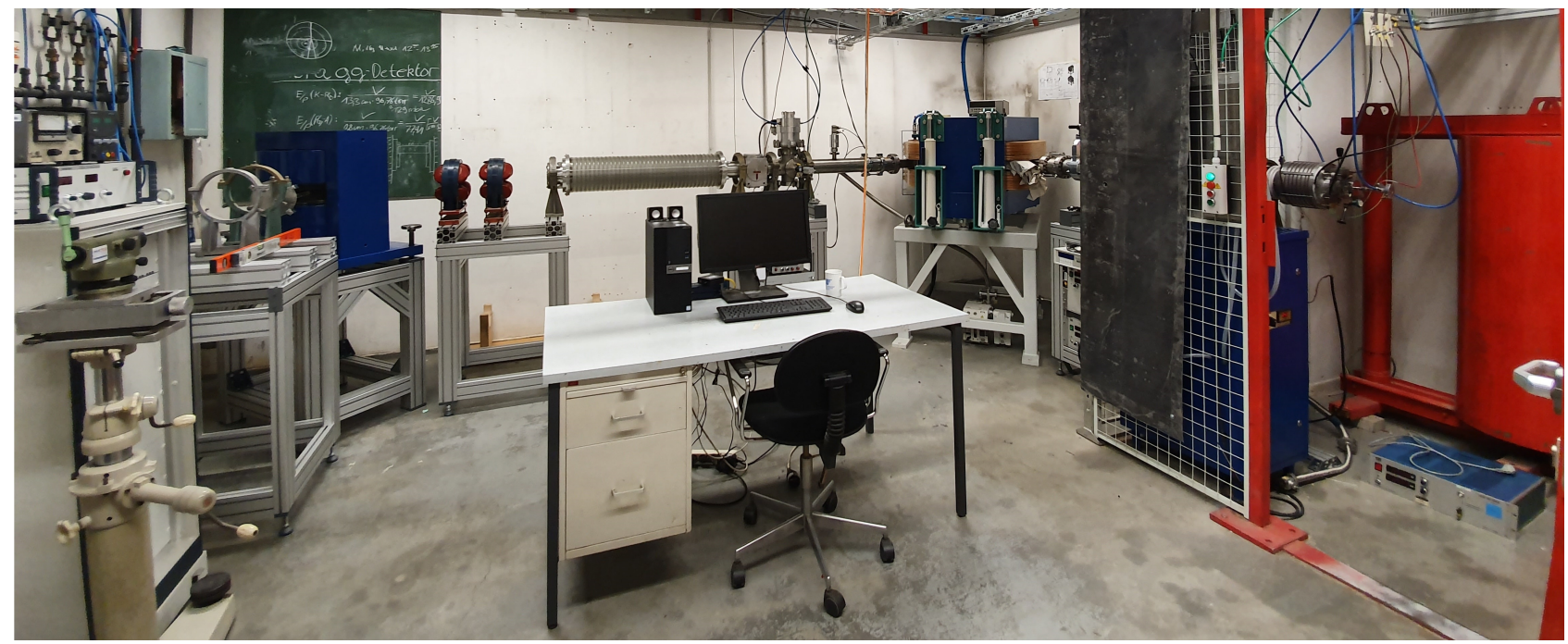

Figure 2. The new $100 \mathrm{kV}$ Tandem accelerator. Shown is (from right to left): the ion source, the double focusing $90^{\circ}$ analyzing magnet, $\rho=500 \mathrm{~mm}$, the $1 \mathrm{~m}$ acceleration tube (without grounded protection housing), the quadrupole doublet and the $90^{\circ}$ analyzing magnet, $\rho=190 \mathrm{~mm}$. Beam line components between accelerator and second magnet had not been installed.

AMS project for quantification of ${ }^{14} \mathrm{C}$ content in reactor graphite by use of the new gas handling system. The accelerator can be installed independently to the other accelerators with its own $\mathrm{SF}_{6}$ gas system, Fig. 3 .

Two main components of the 3 MV AMS system from Jena will be used for the new setup: the accelerator and the high energy mass spectrometer. The HVEE 3 MV Tandetron 4130 accelerator is furthermore used at the National Ocean Sciences AMS Facility at Woods Hole, Massachusetts (USA) [10] and the Leibniz-Laboratory for Radiometric Dating and Stable Isotope Research, ChristianAlbrechts-University of Kiel (Germany) [11]. The accelerator is designed in a T-shaped geometry with a $\mathrm{SF}_{6}$ isolated pressure tank. The system was designed for high current ion beams for implantations, activations and other ion beam techniques. A parallel-fed Cockkroft-Walton power supply, driven by $50 \mathrm{kHz}$, is used for the high voltage generation. The terminal voltage is stabilized by a generating volt meter or by slit feedback signals from the stable ${ }^{13} \mathrm{C}$ ion beam. The voltage ripple is reported to be lower than $40 \mathrm{~V}$ [12]. For the stripping process an Ar gas stripper is used with a circulation pumping unit and differential pumping units at each end of the stripper baffle [12]. Electrons and particles from charge changing processes or collisions with electrode surfaces are suppressed by the inclined electrostatic field structure of the acceleration tubes and by magnetic suppressors [10, 13]. On the high energy side, an electrostatic quadrupole doublet focuses the ion beam to the object slits in front of the double focusing $110^{\circ}$ magnet. Two offset Faraday-cups for the measurement of ${ }^{12} \mathrm{C}$ and ${ }^{13} \mathrm{C}$ are mounted in the focal plane, as well as image slits for $\mathrm{ME} / \mathrm{q}^{2}$ selection. For $\mathrm{E} / \mathrm{q}$ selection a $33^{\circ}$ electrostatic analyzer is used to select a $\mathrm{M} / \mathrm{q}$ value.

One possibility for the installation of the new $3 \mathrm{MV}$ Tandetron accelerator is parallel to the $\mathrm{SF}_{6}$ storage tank in the second basement of the accelerator building, see figure 3. This opens two opportunities: (i) to couple the new injection system additionally to the 6 MV AMS System and (ii) to build up new beamlines for future applications in the neighboring hall, e.g. ion beam techniques for material analysis. An attractive arrangement of available components uses the $90^{\circ}$ double focusing magnet from the new $100 \mathrm{kV}$ accelerator and the $20^{\circ}$ switching magnet of the Cologne duoplasmatron test bench. With this switching magnet different injection sources could be used: (a) one standard cesium sputtering ion source for solid and gaseous samples, (b) one duoplasmatron for $\mathrm{He}^{-}$ions and (c) an ion beam cooler, for the development of chemical reaction suppression of isobars like ${ }^{90} \mathrm{Zr}$ for ${ }^{90} \mathrm{Sr}$ measurement and for photo laser detachment of ${ }^{26} \mathrm{MgO}^{-}$for ${ }^{26} \mathrm{AlO}^{-}$injection [14].

\section{Conclusion and Outlook}

Accelerator mass spectrometry provides a fast and reliable alternative for the determination of long lived betaemitters which are difficult to measure with standard techniques like liquid scintillation counting. CologneAMS has started to build up dedicated infrastructures for nuclear waste management measurements.

An automated $\mathrm{CO}_{2}$ gas handling and injection system for accelerator mass spectrometry was developed. It is designed to dilute the sample $\mathrm{CO}_{2}$ with blank gas in a mixing volume. In the next project phase, different dilution series will be done with standard material, to show the measurement strategy of high ${ }^{14} \mathrm{C}$ concentrations. The proof of the setup will be performed after that, by measurement of test graphite samples irradiated with defined neutron fluences at the TRIGA reactor Mainz. Finally real graphite-reactor samples will be measured from different German graphite moderated nuclear-reactors.

An $100 \mathrm{kV}$ accelerator system was developed to measure samples with high ${ }^{14} \mathrm{C}$ content. The system can be used to carry out tests of the gas handling system. 

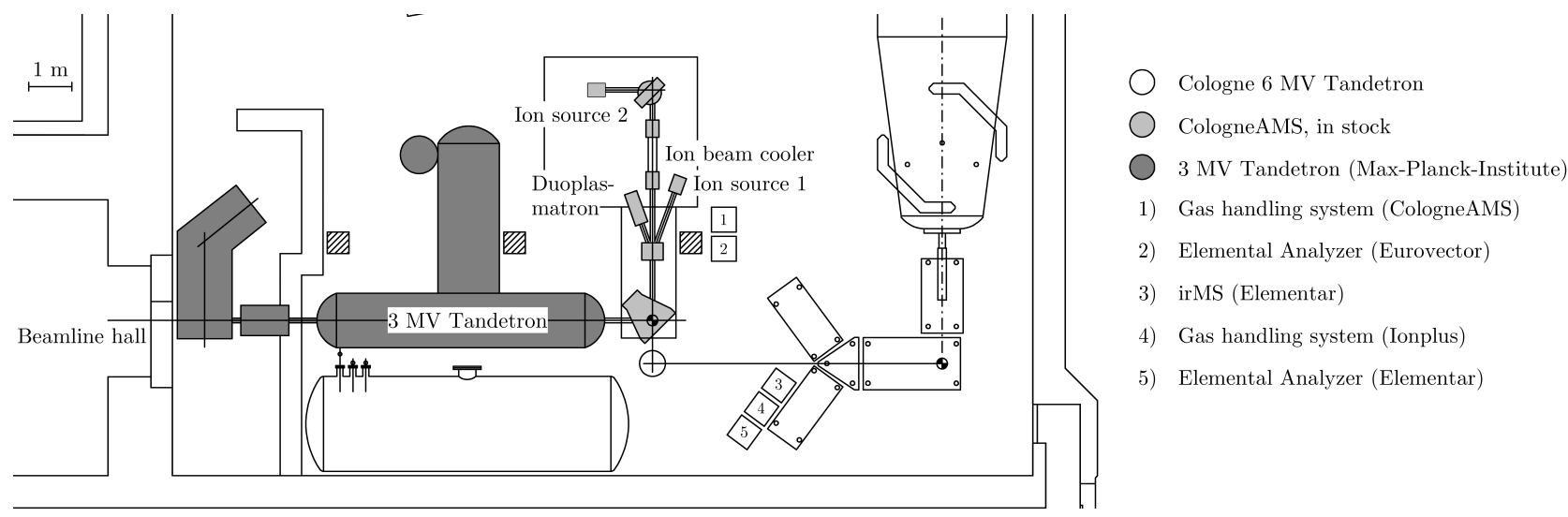

Figure 3. One possibility for the installation of the new $3 \mathrm{MV}$ Tandetron accelerator in the second basement of the accelerator building of the Institute for Nuclear Physics of the University of Cologne. Shown are the new components from the MPI (dark gray) and the available components (light gray). Additional beamlines for future applications can be built up in the neighboring beamline hall.

The installation of a new $3 \mathrm{MV}$ accelerator opens up two opportunities; nuclear waste management AMS measurements, e.g. ${ }^{14} \mathrm{C}$, and ion beam techniques for material analysis.

\subsection{Acknowledgement}

We thank Dr. Axel Steinhof, from Max-Planck Institute for Biogeochemistry Jena (Germany), for his personal commitment to enable the purchase of the $3 \mathrm{MV}$ accelerator. The project is partly funded by the BMBF (funding number $1559410 \mathrm{~B})$.

\section{References}

[1] D. Vulpius, K. Baginski, B. Kraus et al., Nucl. Eng. Des. 265, 294-309 (2013).

[2] W. von Lensa, D. Vulpius, H.-J. Steinmetz et al., Atw. Internationale Zeitschrift fuer Kernenergie 57 263-269 (2011).

[3] A. Dewald, S. Heinze, C. Feuerstein et al., EPJ Web Conf. 6303006 (2013).
[4] R. Spanier, PhD thesis, University of Cologne (2019).

[5] M. Schiffer, A. Stolz, D. Lopez et al., Global and Planetary Change 184103053 (2020).

[6] A. Stolz, A. Dewald, S. Heinze et al., Nucl. Instrum. Methods B 439 70-75 (2019).

[7] M. Ruff, S. Fahrni, H. W. Gäggeler et al., Radiocarbon 52 1645-1656 (2010).

[8] A. Steinhof, Nucl. Instrum. Methods B 331 238-242 (2014).

[9] J. R. Southon, D. E. Nelson, J. S. Vogel, Nucl. Instrum. Methods B 52 370-374 (1990).

[10] K. H. Purser, T. H. Stick, R. K. Purser, Nucl. Instrum. Methods B 52 263-268 (1990).

[11] M.-J. Nadeau, A. E. Litherland, A. Rieck et al., Nucl. Instrum. Methods B 223-224 346-352 (2004).

[12] K. H. Purser, T. Smick, A. E. Litherland et al., Nucl. Instrum. Methods B 35 284-291 (1988).

[13] K. H. Purser, Radiocarbon 34 458-467 (1992).

[14] M. Martschini, J. Pitters, T. Moreau et al., Nucl. Instrum. Methods B 415 9-17 (2017). 